5 Myles PS, Hunt JO, Nightingale CE, et al. Development and psychometric testing of a quality of recovery score after general anesthesia and surgery in adults. Anesth Analg 1999; 88: 83-90.

\section{Anesthesia in the prone lithotomy position}

\section{To the Editor:}

We present our experience of the anesthetic management of patients in the rarely used prone lithotomy position (Figure).

During surgery, the prone position, if correctly applied, ensures free abdominal movement, is not associated with adverse effects on respiratory mechanics and improves lung volume and oxygenation. ${ }^{1,2}$ The lithotomy position, when superimposed on the prone position, improves cardiac output and hemodynamics, compensating for the decreased cardiac output due to impaired venous return in the prone position. ${ }^{3}$ Repair of a vesico-vaginal fistula under balanced anesthesia was performed in the prone lithotomy position in three ASA physical status I and II patients. In all cases, non-invasive blood pressure, central venous presure (CVP), ECG, airway pressure, end tidal carbon dioxide and oxygen saturation were monitored and changes in hemodynamic and respiratory variables were recorded. After the change of position to prone lithotomy, all variables remained stable except for a rise in airway pressure in the range of +1 to $+2 \mathrm{~cm} \mathrm{H}_{2} \mathrm{O}$ in one patient but without change in end tidal carbon dioxide tension and oxygen saturation. Another patient had a moderate rise of $\mathrm{CVP}\left(+2\right.$ to $\left.+5 \mathrm{~cm} \mathrm{H}_{2} \mathrm{O}\right)$. Peripheral nerve injury did not occur in any of the patients. The variables returned to baseline levels after patients were placed in the supine position after surgery, before extubation.

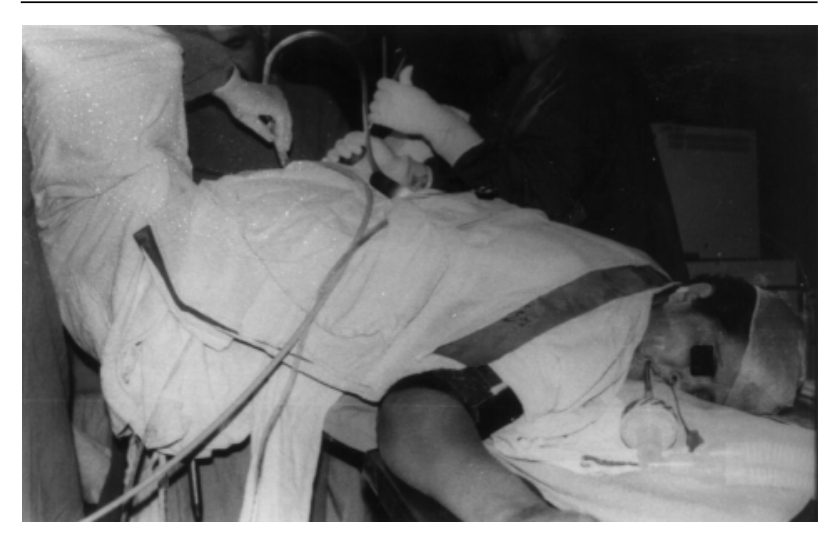

FIGURE Surgical repair of vesico-vaginal fistula in the prone lithotomy position.
On the basis of the experience gained during these three cases, we suggest that surgery in the prone lithotomy position is not associated with major cardiovascular or respiratory derangements intraoperatively.

Shashi Srivastava MD

Chandra Kant Pandey MD

Lucknow, India

\section{References}

1 Pelosi P, Croci M, Calappi E, et al. The prone positioning during general anesthesia minimally affects respiratory mechanics while improving functional residual capacity and increasing oxygen tension. Anesth Analg 1995; 80: 955-60.

2 Pelosi P, Croci M, Calappi E, et al. Prone positioning improves pulmonary function in obese patients during general anesthesia. Anesth Analg 1996; 83: 578-83.

3 Cucchiara RF, Ronal JF. Patient positioning. In: Miller RD (Ed). Anesthesia, 5 ed. New York: Churchill Livingstone Inc., 1999: 1017-32.

4 Thompson JD. Vesicovaginal and urethrovaginal fistula. In: Rock JA, Thompson JD (Ed). Te Linde's Operative Gynecology, $8^{\text {th }}$ ed. Philadelphia: Lippincott-Raven,

1997: 1175-1205.

\section{Cost and resource implications of under- graduate simulator-based education}

To the Editor:

Medical education has been recognized as a costly undertaking especially when innovations are introduced. Rothman and Cohen point out that standardized assessments like the Objective Structured Clinical Examinations (OSCE) are logistically complex and expensive. ${ }^{1}$ Interest in the use of anesthesia simulators for both educational and assessment purposes has increased as more medical schools acquire this technology. However, issues related to the financial and faculty resources cannot be ignored.

TABLE Estimation of operational costs

\begin{tabular}{lll}
\hline Item & Annual cost & $\begin{array}{l}\text { Cost per } \\
\text { student } \\
(C d n \$)\end{array}$ \\
\hline Simulator equipment and supplies & $3,500.00$ & 19.77 \\
Computer operator & $4,500.00$ & 25.42 \\
$\mathrm{CO}_{2}$ cylinders & 300.00 & 1.69 \\
Videotapes & 180.00 & 1.02 \\
Office equipment and supplies & 324.00 & 1.83 \\
Total & $8,804.00$ & 49.73 \\
\hline
\end{tabular}

